OBETS. Revista de Ciencias Sociales

Vol. 9, n. ${ }^{\circ}$ 2, 2014; pp. 333-359

ISSN: $1989-1385$

DOI: 10.14198/OBETS2014.9.2.04

\title{
TEORÍAS SOBRE LA GLOBALIZACIÓN: UNA EVALUACIÓN CRÍTICA ${ }^{1}$ THEORIES ON GLOBALIZATION: A CRITICAL APPRAISAL
}

\author{
Antonio Martín Cabello \\ Departamento de Derecho Público, Ciencia Política y Sociología, \\ Facultad de Ciencias Jurídicas y Sociales \\ Universidad Rey Juan Carlos, España \\ antonio.martin@urjc.es
}

\begin{abstract}
Resumen
Este artículo trata de revisar la abundante y dispersas literatura científica con el objetivo de identificar las principales explicaciones del proceso de globalización. El objetivo es construir una perspectiva meta-teórica que nos permita desarrollar una teoría de la globalización más analítica para evitar las trampas del debate político. Las diferentes teorías son analizadas utilizando una aproximación histórica y analítica para detectar el mecanismo explicativo propuesto para interpretar la globalización. Se han encontrado cuatro aproximaciones principales: la tesis del comercio, la tesis de la modernización, la tesis tecnológica y la tesis del capitalismo. Después, el artículo trata de hacer una evaluación crítica de las cuatro tesis sobre la globalización. Por último, concluye discutiendo las críticas posmodernas al carácter moderno de la teoría de la globalización.
\end{abstract}

Palabras clave: Capitalismo; comercio internacional; modernidad; tecnología; ventaja comparativa.

\footnotetext{
${ }^{1}$ Este artículo forma parte de una investigación más amplia para la que se contó con financiación a través de una Beca de movilidad postdoctoral para PDI concedida por la URJC y el Banco de Santander Universidades en su convocatoria 2012-13, que se realizó en el Institut für Asien und Afrikawissenschaften de la Humboldt-Universität zu Berlín (Alemania). El autor desea agradecer el apoyo y comentarios recibidos durante la misma del profesor Boike Rehbein.
} 


\begin{abstract}
This paper tries to review the abundant and scattered scientific literature in order to identify the main scientific explanations of the globalization process. The global objective is to build a meta-theoretical perspective that allows us to develop a more analytical globalization theory to avoid the political debate traps. Diverse theories are analysed using a historical and analytical approach to detect the explanatory mechanism proposed to interpret globalization. Four main approaches have been found: the thesis of international trade, the modernization thesis, the technological thesis and the thesis of capitalism. Afterwards, the paper tries to make a critical appraisal of the four globalization thesis. Finally, the article concludes discussing the postmodern criticism to the modern character of the globalization theory.
\end{abstract}

Key-words: Capitalism; Comparative Advantage; International Trade; Modernity; Technology.

\title{
Extended abstract
}

The goal of this paper is to review the wide-ranging and diffuse scientific literature on the globalization process in order to identify its main explanations. The intention is to construct a meta-theoretical viewpoint that will enable the development of a more analytical theory of globalization that avoids the pitfalls of political debate. Specifically, the aim is to fill a gap in the theory of globalization: the lack of systemization in the different theoretical approaches. This might seem paradoxical, since plentiful literature exists on the subject. The idea is to describe the underlying model behind different theoretical constructions in relation to their essential explanatory mechanisms, in order to subsequently make a critical analysis of their analytical and empirical bases. In short, it is a question of answering the questions posed by Roland Robertson: "What drives the globalization process? What is its "motor force'?" (2001: 461). As part of the analysis of these theories, a review has been made of the most important work most frequently quoted by the scientific community, which tries to explain globalization as an all-encompassing process of change. This includes work written by some of the most outstanding social-science analysts in the fields of anthropology (Appadurai, 1996), philosophy (Safranski, 2005), sociology (Bauman, 1998; Beck, 2000; Berger and Huntington, 2002; Casttels, 2000; Giddens, 1993, 2000; Ritzer, 2004; Robertson, 1992; Urry, 2002), economics (de la Dehesa, 2006; Stiglitz, 2002, 2006), political science (Barber, 1996; Held and McGrew, 2002, 2007) and human geography (Anderson, Brook and Cochrane, 1995; Harvey, 2008) among others. In order to systemize the range of theories of globalization, a classification is set up to attempt to group them according to the "explanatory mechanism" they propose explicitly or implicitly, when presenting their development. The mechanism is frequently mono-causal, although this is not necessarily the case in every theory. Four major theses have been detected in accordance with the explanatory mechanism used to explain the globalization process. They can be referred to as follows: the commercial interchange thesis, the modernization thesis, the technology thesis, and the capitalism thesis. 
First, the commercial interchange thesis argues that it is a process of increasing interconnection based on an historic growth in commerce on a planetary level. The origins of commercial interchanges can be found in the natural tendency of human beings towards interchange. This is the predominant version describing globalization in the main economic schools. Specifically, globalization, it is argued, merely reflects the expansion of the markets worldwide. Without any barriers or distortions, such as imperfect information or the intervention of third agents, this process would arrive at a situation of perfect beneficial balance for all the players in the market. Free trade would ensure the supply and demand of goods reach a balance in which everyone involved obtains benefits, thereby reducing possible initial inequalities. The mechanism making this possible would be comparative advantage.

The second thesis posits that globalization involves the expansion of the modernization process, originally emerging in Europe, worldwide. Modernization undoubtedly implies a technical dimension, commercial interchange and capitalist accumulation, but also includes political elements such as democracy, the rule of law and the control of physical violence, as well as cultural elements such as secularization and individualism. Globalization viewed from this perspective entails the expansion of a civilizing model, summed up by the word modernity, all around the planet and its assimilation in nonwestern peoples.

The third thesis, one of the most popular and widespread, looks to explain globalization from an essentially technical basis. This position postulates that physical communications and Information and Communications Technologies (ICTs) are behind globalization.

The last thesis emphasizes the expansion of capitalism, which it views as a broader phenomenon than the market, and as the main engine driving globalization. These authors typically believe capitalism is an institutional phenomenon over and above simple interchange. They regularly cite at least three major elements among conditions required for the existence of capitalism: a monetary system that enables the existence of money in the form of banking credit, commercial exchanges and the production of goods in the private business system. The existence of a State that provides the necessary backing and institutional coverage for setting up a capitalist system is usually added. In short, this position argues that the development of capitalism as an economic (and political) system would explain globalization, with this constituting the latest phase in its development.

The paper then makes a critical evaluation of the four theses of globalization. The commercial interchange thesis has been attacked on five flanks: its ideological assumptions, the naturalization of the economic system, the role of the State, the results of globalization and the mechanism regulating international trade, or in other words, the theory of comparative advantage. The modernization thesis has been criticized because of its holistic, euro-centric nature and because of the impossibility of finding causal relationships using this model. The technology thesis has been censured for its technological determinism. Lastly, the capitalism thesis has been criticized because it exaggerates 
the importance of the "rich and powerful" as essential agents in the globalization process, as a result of its left-wing ideological basis, and because the consequence of the globalization process is the opposite of what the thesis postulates.

The paper concludes that the four theses under discussion operate on two levels of abstraction. The first describes the cause of globalization according to two relatively simple and homogenous variables: technology and commercial interchange. An increase in these variables inevitably leads to globalization. The second looks to multi-causal models, which usually combine these simple variables in more analytically complex models. Capitalism is therefore defined as a construction that unites several institutions: commercial interchange, markets, money, credit and private business. Modernity involves new technologies, a capitalist economy, a democratic and rational State, active citizenry and a culturally secular and individualist society, among other institutional features. The combination of these variables in varying degrees conforms the mechanism that explains the globalization process. Whatever the case may be, all these theories are unified by their attempts at constituting one "big theory" to explain the globalization process as a whole.

This big theory aims to create an all-encompassing narrative, which provides a "primary cause" for the explanations of the social phenomena of our time. It is therefore a theory deeply imbedded in modern thought. That is why it has been attacked from the postmodern theoretical viewpoint, which rather than rejecting specific aspects of the theses presented, tends to reject the very possibility of an all-encompassing globalization theory. In the opinion of the postmodernists, the age of grand narratives is behind us. These normally just legitimize processes, set in motion by Caucasian men, rather than truly describing worldwide dynamics. Consequently, they exclude non-western peoples, who are obliged to participate in a narrative written by and for the West.

Moreover, a typical feature of the theory of globalization is how it commonly unites regulatory and de facto elements. Globalization theory is therefore constituted as a powerful justification for economic, political or social action, and establishes a corrosive debate between those supporting the process and those who reject it. In short, globalization theory as reflected here is faced with both specific and general problems, which restrict its analytical and descriptive capacity. Its success could reside more in its capacity to draw up an enormously valuable cognitive map for members of societies undergoing profound and accelerating economic, political and cultural change, than in its analytical capacity to describe this reality in scientific terms.

\section{INTRODUCCIÓN}

El fenómeno de la globalización ha provocado, como es sabido, uno de los debates más intensos y fructíferos dentro de las ciencias sociales de los últimos tiempos. Ahora bien, las teorías sobre la globalización están sujetas al paso del tiempo y, cómo no, también a las modas académicas. Esto ha producido que recien- 
temente algunos autores hayan rechazado la teorización sobre la globalización como un camino fructífero para explicar las relaciones internacionales y hayan dictaminado su defunción (Rosenberg, 2005). Sin embargo, y sin entrar en el debate entre globalizadores y escépticos (Held y McGrew, 2002), lo cierto es que es un concepto vivo en el debate académico, político y social. En este sentido es posible afirmar que es una perspectiva que ha modificado profundamente la visión tradicional de las ciencias sociales permitiendo la superación del marco de referencia nacional (Albert, 2007) y que su desaparición como teoría no parece cercana (Bude y Durrschmidt, 2010). En 2006 un estudio recogió 114 definiciones diferentes del término globalización (Al-Rodhan, 2006) y existe un amplio corpus teórico sobre el fenómeno con múltiples autores de referencia (Boli y Lechner, 2009; Jones, 2010; Stohl, 2005). Las teorías sobre la globalización, además, cruzan las fronteras disciplinarias y ayudan a construir los modelos teóricos de todas las ciencias sociales.

Este artículo pretende cubrir una carencia de la teoría de la globalización: la falta de sistematización de sus diferentes aproximaciones teóricas. Esto puede parecer paradójico, porque la producción sobre el tema es muy abundante. Se pretende describir el modelo subyacente a las distintas construcciones teóricas en torno a su mecanismo explicativo fundamental para posteriormente realizar una crítica sobre sus fundamentos analíticos y empíricos. Se trata, en definitiva, de responder a las preguntas que planteó Roland Robertson: “¿Qué impulsa el proceso de globalización? ¿Cuál es su fuerza motriz?” (2001: 461).

Para ello, en primer lugar y tras realizar una breve descripción de la metodología, el artículo presenta las cuatro tesis principales que se han identificado dentro de las ciencias sociales a la hora de explicar el proceso de globalización. En segundo lugar se discutirán las principales críticas que se han realizado a cada una de estas tesis, intentando sistematizarlos en el mayor grado posible. Finalmente se planteará en las conclusiones la existencia de una crítica general que más allá de las virtudes o defectos de las diferentes tesis, plantea la necesidad de revisar toda la teoría de la globalización como un intento postrero de utilizar categorías analíticas modernas en un entorno intelectual posmoderno que ya no las contempla como básicas para las ciencias sociales.

\section{METODOLOGÍA}

Un aspecto peculiar de la teoría de la globalización es su carácter de "gran teoría", que vive en libros y monografías más que en artículos científicos, dedicados en su mayor parte a analizar aspectos concretos del proceso de globalización o, a lo sumo, a intentar construir teorías de alcance medio en el sentido que le confirió Robert K. Merton al término. Posee un carácter de relato totalizador, 
que sirve como ultima explicación de todo tipo de fenómenos económicos, políticos, sociales o culturales y de justificación de actuaciones y políticas concretas. Por ese motivo la globalización se constituye en un campo de continuas y virulentas discusiones teóricas, ideológicas y políticas (Trigo, 2004). Es uno de los últimos grandes relatos de sobre la modernidad tardía.

En el análisis de estas teorías se han revisado las obras más relevantes y citadas por la comunidad científica que intentan explicar la globalización como un proceso totalizador de cambio. Entre ellas se encuentran trabajos escritos por algunos de los más destacados analistas sociales en el campo de la antropología (Appadurai, 1996), filosofía (Safranski, 2005), sociología (Bauman, 1998; Beck, 2000; Berger y Huntington, 2002; Casttels, 2000; Giddens, 1993, 2000; Ritzer, 2004; Robertson, 1992; Urry, 2002), economía (de la Dehesa, 2006; Stiglitz, 2002, 2006), ciencia política (Barber, 1996; Held y McGrew, 2002, 2007) o, entre otros, geografía humana (Anderson, Brook y Cochrane, 1995; Harvey, 2008). Para sistematizar las diferentes teorías sobre la globalización se propone una clasificación que trata de agruparlas en función del "mecanismo explicativo" que plantean, explícita o implícitamente, a la hora de exponer su desarrollo. El mecanismo es con frecuencia monocausal, aunque esto no ocurre necesariamente en todas las teorías. Se han detectado cuatro grandes tesis en función del mecanismo explicativo que utilizan para explicar el proceso de globalización. Es posible denominarlas: la tesis del intercambio comercial, la tesis modernizadora, la tesis tecnológica y la tesis del capitalismo.

Dentro la descripción de cada una de las tesis se ha intentado presentar sus principales líneas analíticas, ligándolas con un recuento histórico de su gestación. El objetivo es presentar cada una de las mismas en su contexto para posteriormente poder enmarcar las principales críticas de las que han sido objeto. En las conclusiones se argumentarán que la principal crítica a estas tesis deriva del posmodernismo, que rechaza la idea de construir una gran teoría (Ritzer, 2004). Se trata de una crítica meta-teórica que afirma la imposibilidad de construir una teoría de la globalización como un gran relato de la modernidad.

\section{TESIS DEL INTERCAMBIO COMERCIAL}

Una de las tesis más influyentes a la hora de explicar la globalización sostiene que esta es un proceso de creciente interconexión basado en un aumento histórico del comercio a escala planetaria. El origen de los intercambios comerciales descansaría, como afirmaba Adam Smith (1723-1790), en la propensión natural del ser humano hacia el intercambio. Destacan dos escuelas económicas a la hora de situar los intercambios comerciales como la base de la 
globalización, que además suelen contemplar de un modo positivo. Desde la escuela neoclásica y monetarista se ha afirmado que la globalización no es sino la extensión de los mercados a escala mundial. Este es un proceso en el cual si no existen barreras o distorsiones, por ejemplo, una información imperfecta o la intervención de terceros agentes, se llegará a una situación de perfecto equilibro beneficiosa para todos los partícipes en el mercado. El libre comercio producirá que la oferta y la demanda de bienes lleguen a un equilibro en el cual todas las partes implicadas obtengan beneficios, reduciendo las posibles desigualdades de partida. El mecanismo que posibilitaría esto sería la ventaja comparativa.

Según esta teoría, cuya versión canónica propuso el año 1817 David Ricardo (1772-1823) en Inglaterra, el libre comercio internacional permitiría que cada nación se especializara en producir aquellos productos y servicios para los que está especialmente dotada, por los que obtendría rentas en el mercado internacional. Con las mismas compraría el resto de productos y servicios que precisara a menor costo que si los tuviese que producir por sí misma. Este sistema haría que todas las naciones ganaran con la apertura de los mercados y que a largo plazo se produjera una equiparación de rentas (steady state). La globalización sería, por tanto, un proceso con el que los actores individuales buscando su propio beneficio se especializarían y a través del libre comercio alcanzarían una situación de equilibrio en la cual todos saldrían ganando. Posteriormente, en 1933, los economistas suecos Bertil Ohlin (1899-1979) y Eli Hecksher (1879-1952) reformularon este planteamiento, en el llamado modelo HecksherOhlin, manteniendo sin embargo el carácter beneficiosos de la especialización y del comercio internacional para todas las partes implicadas.

Desde otra óptica, los economistas de la llamada Escuela Austriaca -Ludwig von Mises (1881-1973) o Friedrich A. Hayek (1899-1992)-, describían los mercados como un proceso espontáneo, que no admitía planificación y en el que no se llegaba a un equilibro (Huerta de Soto, 2010). La globalización desde esta perspectiva implicaría una extensión natural de los mercados, en la que aumentan su tamaño y complejidad hasta adquirir una dimensión global. Un epígono de esta tendencia afirma actualmente que, por tanto, "no es un fenómeno nuevo, sino que se trata de un proceso evolutivo, que emerge espontáneamente de la interacción de diversos individuos en el mercado y cuyo resultado presenta un orden abstracto o extendido que ninguno de esos individuos tenían en cuenta al actuar" (Ravier, 2012: 23). El proceso de globalización resultará beneficioso siempre que el Estado no intervenga, pues se ve como un desarrollo propio de los mercados en el que el Estado no tiene más papel que entorpecer su extensión. El fundamento de este proceso descansaría en el 
comercio, que es una actividad anterior incluso a todas las demás tareas productivas.

En lo que coinciden ambas corrientes, si bien la segunda de un modo más marcado, es en la consideración del Estado como un peligro para el desarrollo "equilibrado" y "espontáneo" de los mercados y por extensión de la globalización. Además ambas coinciden en valorar positivamente la globalización como prolongación del mercado capitalista, lo cual supone ventajas evidentes para los actores implicados que mejoran su situación inicial.

Los defensores del libre comercio y la teoría de la ventaja comparativa fueron especialmente activos durante el siglo XIX, especialmente durante la denominada "primera globalización" que se ha datado entre 1890 y 1914 (Bayly, 2010). Posteriormente se produjo un reflujo, coincidiendo con las dos Guerras Mundiales, que supuso un aumento del proteccionismo nacional y en el plano teórico la aparición de dudas acerca de la teoría de la ventaja comparativa y de su papel beneficioso para todas las partes implicadas en el comercio mundial. El consenso de postguerra y el keynesianismo trajeron una reapertura de los mercados mundiales que se solidificó en torno a los acuerdos de libre comercio (GATT). La crisis de los años 70 fue un reto para la consolidación de un sistema de libre comercio mundial. En un informe dirigido a la Comisión Trilateral se planteaba en 1975 que:

Por regla general, el cuarto de siglo inmediatamente posterior a la Segunda Guerra Mundial fue testigo de la eliminación de las restricciones al comercio y la inversión, y de una apertura general de las economías de los países industrializados, capitalistas. Sin embargo, en tiempos de escasez económica, inflación y posibles recesiones económicas a largo plazo, aumentan las presiones a favor del nacionalismo y el neo-mercantilismo y los sistemas políticos democráticos se ven particularmente vulnerables a la presión de esos grupos de la industria, de las localidades y de las organizaciones laborales, que se ven desfavorablemente afectados por la competencia extranjera (Crozier, Huntington y Watanuki, 2012: 325-326).

Para combatir dichas "presiones" se orquestó toda una respuesta con el objetivo de favorecer el libre comercio y la globalización, que tuvo su máxima expresión en el Consenso de Washington (Williamson, 1993). Estas políticas, firmemente apoyadas por los gobiernos conservadores de Estados Unidos e Inglaterra y seguidas por la mayoría de las economías más desarrolladas, tuvieron éxito y en 1994 se creó la Organización Mundial del Comercio, que profundizaba en los acuerdos de libre comercio y les daba mayor cobertura institucional (Martín-Cabello, 2013). En todo caso, pese a su largo recorrido histórico la tesis del intercambio comercial ha mantenido básicamente inalteradas 
sus premisas de partida, a saber, que la especialización y división internacional del trabajo combinada con un comercio internacional abierto -sin interferencias estatales- es fruto de la propensión natural del ser humano a comerciar y crear mercados cada vez más amplios y que sus consecuencias son beneficiosas para todos los implicados. La globalización como expresión última de esta dinámica retendría este carácter positivo.

\section{TESIS MODERNIZADORA}

La segunda tesis plantea que la globalización supone la extensión del proceso modernizador surgido originalmente en Europa a escala planetaria. La modernización implicaría una dimensión técnica, de intercambio comercial y de acumulación capitalista, sin duda, pero también aspectos políticos como la democracia, el imperio de la ley o el control de la violencia física, y culturales como la secularización o el individualismo. Esta visión estuvo ampliamente extendida dentro de la Historische Schule der Nationalökonomie en Alemania, de la escuela institucionalista económica norteamericana y de la corriente sociológica principal. En general, y pese a sus diferencias, contemplaba que la economía se encontraba integrada en una sociedad y una cultura histórica concreta. Por lo tanto, los desarrollos económicos como el mercado, el capitalismo o el comercio internacional debían estudiarse conjuntamente con el resto de instituciones sociales que permitían su existencia.

Quizá la versión más famosa de esta tesis fue la desarrollada por Max Weber a finales del siglo XIX y principios del XX. Hacía hincapié, entre otros, en los factores culturales como elementos codeterminantes en la aparición del capitalismo (Weber, 1998). Pensaba que la ética protestante influyó en un primer momento en la aparición de un ethos capitalista. En consecuencia, la cultura de los distintos países influía en el éxito del sistema capitalista en ese territorio. Sostenía, asimismo, que históricamente el capitalismo era una forma específica de economía, que implicaba un conjunto de instituciones en la esfera económica: contabilidad racional, propiedad privada, técnica racional, libertad mercantil, trabajo libre y mercantilización de la economía; y en las esferas política, social y cultural como el Estado racional, con su derecho y burocracia racionales, o una ideología propia del capitalismo (Weber, 2011).

La globalización vista desde esta perspectiva conllevaría la extensión de un modelo civilizatorio, resumido en la palabra modernidad, por todo el planeta y su incorporación por parte de pueblos no occidentales. Las tesis modernizadoras fluctúan desde un modernismo difusionista, en el que el resto de países van incorporando poco a poco las instituciones Occidentales, hasta la teoría de las modernidades múltiples, para la cual existen diferentes caminos 
o vías hacia la modernidad, que puede desarrollarse en entornos culturales muy diversos. La primera versión se encontraba ampliamente extendida después de la Segunda Guerra Mundial con las llamadas teorías del desarrollo o de la modernización (Curran y Park, 2000: 3). De hecho, la globalización era vista como una teoría del desarrollo (Reyes, 2001). Se planteaba que todos los países, una vez superadas las barreras institucionales y culturales locales, podían llegar a convertirse en países desarrollados similares a los occidentales. Solamente había un camino hacia la modernidad, un progreso lineal que consistía en la asunción de las instituciones occidentales.

En esta línea, el historiador Niall Ferguson (2012) ha interpretado tardíamente la globalización, que supone un retroceso o una decadencia de Occidente y un avance del resto del mundo, como un proceso en el que países no occidentales han conseguido "descargarse" las instituciones clave (a las cuales denomina killer aps o aplicaciones asesinas) que permitieron el desarrollo occidental: la competencia en la esfera de la economía, la ciencia, la medicina moderna, la sociedad de consumo y la ética del trabajo. De este modo aunque no asumen todo el aparato institucional occidental ni su cultura completa, si incorporan las instituciones clave que permitieron la modernización. Es decir, la globalización sería algo más que economía, pues incluiría la aceptación de las instituciones claves de la modernidad occidental por parte de las naciones no occidentales exitosas. La contraparte la pondrían las naciones fracasadas, que no han conseguido integrar esas instituciones clave.

La segunda versión surgió con posterioridad para tratar de explicar el éxito de países como Japón o los llamados Tigres Asiáticos (Hong Kong, Corea del Sur, Singapur y Taiwán) a la hora de desarrollar un sistema capitalista competitivo sin necesidad de incorporar la cultura y las instituciones occidentales como un todo. Anthony Giddens (1993) planteaba que la modernidad pivota sobre cuatro dimensiones institucionales clave: el capitalismo, el industrialismo, la vigilancia y el poder militar, a los que habría que añadir la cultura. La misma dinámica de la modernidad lleva a su extensión ya que esta es "intrínsecamente globalizadora", lo cual produce que se pueda hablar de cuatro dimensiones institucionales clave de la globalización: el capitalismo mundial, la división internacional del trabajo, el sistema de Estados mundial y el orden militar mundial, sobre los que pivota igualmente la globalización de la cultura. Cree que la modernidad es occidental desde el punto de vista del Estado-nación y de la producción capitalista, ya que son dimensiones institucionales que han aparecido y se han desarrollado allí. Sin embargo, cuando se globalizan pierden esa característica, pues es un proceso abierto de interdependencia en el cual lo no occidental tiene su peso. Así, "se pueden dar muchas 
clases de respuesta cultural a esas instituciones dada la diversidad cultural del mundo en su conjunto" (1993: 163). Dicho de otro modo, la modernidad es adaptativa y adquiere un perfil diferente según el contexto en el que se desarrolla.

Grosso modo, esta versión mantiene que la globalización surge de la expansión de la civilización occidental, europea en un primer momento, por todo el mundo. No se trata simplemente del crecimiento de un sistema económico basado en el intercambio mercantil, sino de la extensión planetaria de un conjunto institucional que configura una forma civilizatoria específica: la modernidad. Esta posteriormente se incorporaría a otras civilizaciones y adquiriría un carácter global.

Esta nueva perspectiva de la modernización rechaza la visión de que el mismo proceso de modernización genera el potencial de evolución compartido por todas las sociedades sino que estima que la modernización o la modernidad son un tipo específico de civilización que surgió en Europa y se expandió a través del mundo, abarcándolo -sobre todo después de la Segunda Guerra Mundial- casi en su totalidad. (...) Al igual que hicieron las civilizaciones históricas en su expansión, el despliegue de la modernidad desafía las premisas simbólicas e institucionales de las sociedades que quedan incorporadas. (...) Estas diferencias se cristalizan en el marco de la incorporación selectiva -y transformación- tanto de las principales premisas simbólicas y formaciones institucionales de la original civilización occidental como de las tradiciones y de la experiencias históricas de sus propias civilizaciones (Eisenstadt, 2010: 99-100).

En consecuencia la globalización además de comercio internacional y flujo de mercancías, capitales y personas supone cambios técnicos, políticos, sociales y culturales que son incorporados a través de una compleja negociación -no simplemente de "descargas" selectivas- en las culturas no occidentales.

\section{TESIS TECNOLÓGICA}

Otra de las tesis, una de las más populares y extendidas, considera que la globalización ha de explicarse fundamentalmente desde su base técnica. Desde esta posición se afirma que las comunicaciones físicas y las Tecnologías de la Información y la Comunicación (TIC) están detrás de la globalización (Castells, 2000; Cebrián, 2000; Langhorne, 2001; Negroponte, 1995). Manuel Castells, uno de los más famosos defensores de esa posición, considera que son fundamentalmente las TIC -entre las que incluye las biotecnologías- las que explican los cambios que conducen hacia la globalización y generan una sociedad basada en los flujos de información que denomina sociedad red. Así, "el núcleo 
de la transformación que estamos experimentando en la revolución en curso remite a las tecnologías del procesamiento de la información y la comunicación" (2000: 57). También se puede citar, entre otros, a Richard Langhorne (2001) para el cual las redes de comunicación, primero físicas con la invención de la máquina de vapor y posteriormente de la información con el hito iniciático de la invención del telégrafo, marcan el punto de partida de la globalización y le confieren su carácter distintivo. En todo caso, para esta tesis el factor fundamental que explica los orígenes y las características actuales de la globalización es la aparición, mejora y extensión de las comunicaciones físicas y sobre todo de las TIC.

En este sentido, las TIC ejercerían su influencia en dos campos diferenciales: la evanescencia de las barreras geográficas de un lado y de los límites temporales de otro. La globalización, en primer lugar, supone el fin o al menos la disminución de la importancia de los límites territoriales (Cairncross, 1997; Virilio, 1997). Se produce un estrechamiento de los límites del planeta en todos los ámbitos de la vida social. La globalización implica, por un lado, la pérdida de la conexión de las sociedades y las culturas con el territorio con el que antes se consideraba unidas de un modo natural y, por otro, su reubicación en nuevos entornos geográficos (García Canclini, 2001). Es por tanto un proceso paradójico que si bien no hace desaparecer el territorio, lugar donde se da la existencia de los seres humanos, sí disminuye su importancia y fomenta la aparición de nuevos espacios donde opera una lógica global. Marc Augé (2000) denomina "no lugares" a estos nuevos espacios globales. Los lugares tradicionales se caracterizaban por ser históricos, relacionales y generadores de identidad, mientras que los no lugares no pueden definirse así en modo alguno. Cita algunos de estos espacios: las cadenas hoteleras, los complejos vacacionales, los medios de transporte, los campos de refugiados, los centros comerciales o los parques de atracciones. En general la experiencia del viaje resulta arquetípica de estos no lugares, como nuevos espacios sin historia en los que no se establecen relaciones humanas generadoras de identidad. Friedman (2003) habla de la "experiencia de volar" y Echeverría (1999) de "los señores del aire" como metáfora de este espacio de flujos asociado al transitar por todo el planeta.

También supone un nuevo modo de encarar nuestras relaciones con el tiempo, preso de ese estrechamiento del espacio. Manuel Castells denomina "tiempo atemporal" a este cambio, que se identificaría por romper los ciclos biológicos tradicionales y la temporalidad social lineal asociada al reloj. Crearía, en su lugar, un tiempo simultáneo al enlazar todo el planeta en "tiempo real" y atemporal al diluir la secuenciación y la historia, lo efímero y lo permanente. 
De este modo, "el tiempo atemporal pertenece al espacio de los flujos, mientras que la disciplina temporal, el tiempo biológico y la secuenciación determinada por la sociedad caracterizan a los lugares de todo el mundo" (Castells, 2000: 500). Esta tendencia al desdibujamiento de las restricciones de la geografía y del tiempo supone un estrechamiento "espacio-temporal" (Harvey, 2008). Lo global, en consecuencia, parece existir más allá de las limitaciones que el tiempo y el espacio imponían a los seres humanos en el pasado. Para los defensores de esta tesis, la tecnología está en la base de estos cambios y del proceso de globalización.

\section{TESIS DEL CAPITALISMO}

La última de las tesis pone el énfasis en la expansión del capitalismo, contemplándolo como un fenómeno más amplio que el mercado y como el motor fundamental de la globalización. Estos autores suelen creer que el capitalismo es un fenómeno institucional que va más allá del simple intercambio. Es frecuente que citen entre las condiciones necesarias para la existencia del capitalismo al menos tres grandes elementos: un sistema monetario que permita la existencia de dinero en forma de crédito bancario, el intercambio mercantil y la producción de mercancías dentro del sistema de empresa privada (Ingham, 2010: 68). Suele añadirse la existencia de un Estado que apoye y de la cobertura institucional necesaria para la instalación del sistema capitalista.

Según esta corriente, cuyos orígenes se pueden rastrear en el trabajo de Karl Marx (1818-1883), el capitalismo no sería la forma natural de la economía surgida del intercambio y el comercio. Al contrario, se trataría de un tipo o modelo específico de economía que apareció en un periodo concreto de la historia y que requiere la existencia de un conjunto específico de instituciones. Desde esta óptica existen tres grandes teorías que han tratado de explicar la globalización como un proceso de extensión planetaria del sistema capitalista (Sztompka, 2008: 113-116). En primer lugar se encuentra la teoría del imperialismo tal como la formularon Vladimir Lenin (1870-1924) o Nikolai Bujarin (1888-1938) en los años 30 del siglo pasado. Para ellos, la última fase del capitalismo sería el imperialismo, que busca evitar el colapso del sistema a través de la búsqueda de nuevos mercado y de mano de obrar y de materias primas baratas. Con ese fin, los países capitalistas no dudaban en usar la violencia cuando resultaba necesario a fin de mantener la balanza del comercio mundial a su favor.

En segundo lugar, durante los años 50 y 60 teóricos como André Gunder Frank (1929-2005) o Fernando Cardoso (1931-...) formularon la teoría de la dependencia en Latinoamérica. Planteaban que el comercio internacional se 
fundaba en las relaciones de los países desarrollados, "centro" del sistema, con los países no desarrollados o "periféricos", que se mantenían en una situación de dependencia respecto a los primeros. Como resultado de esta situación, los beneficios del comercio internacional y del proceso de globalización recaían en los países centrales y no en los periféricos.

Finalmente, en tercer lugar, durante los años 70 el propio André Gunder Frank y otros teóricos como Immanuel Wallerstein (1930-...) o Samir Amin (1931-...) desarrollaron la llamada teoría del sistema mundial. Wallerstein (1999, 2011a, 2011b, 2012a, 2012b) sostiene que el mercado no es un hecho natural, sino que ha tenido que ser creado y mantenido constantemente. En su construcción histórica el Estado ha sido básico, ya que la idea de que el mercado crece enfrentado al Estado es mera ideología. El Estado y el mercado han operado conjuntamente en la extensión del sistema capitalista. Al desarrollarse, el capitalismo ha intentado mercantilizar cada vez más facetas de la vida y ha querido hacer aparecer como un hecho dado la institución del mercado.

Distingue diferentes etapas en el desarrollo de una economía-mundo capitalista desde el siglo XVI, donde sitúa sus orígenes, hasta la actualidad. Esta economía-mundo es, a su vez, un tipo de sistema-mundo junto a los imperios mundiales. Se diferenciarían de estos últimos por no tener un centro político definido con fronteras estables, sino múltiples centros. Considera que la globalización es tanto la última etapa en la consolidación de la economía-mundo capitalista como la ideología del capitalismo actual que naturaliza la idea de mercado y de libre comercio (Robinson, 2011).

Samir Amin $(1993,1997,1998)$ sostiene que el libre comercio no genera por sí mismo un sistema capitalista. Históricamente ha existido comercio en múltiples partes del planeta sin que surgiese un sistema capitalista. Este presupone una estructura social, política y económica específica. La globalización sería la palabra que definiría el triunfo de un sistema capitalista a escala mundial que permite la integración de todo el planeta. De hecho, "será el capitalismo el que realizará por primera vez un verdadero y auténtico sistema mundial único, que imprimirá a la historia una aceleración logarítmica" (Amin, 1976: 147). La globalización y consolidación del sistema mundial, en consecuencia, es fruto de la expansión del sistema capitalista.

En resumen, esta posición sostiene que el desarrollo del capitalismo como sistema económico (y político) explicaría la globalización, que se constituiría en la última fase del mismo. La globalización implicaría que las fuerzas del mercado, apoyadas por el Estado, desbordarían las fronteras nacionales y crearían un mercado mundial o global bajo las leyes de la oferta y la demanda. Para conseguirlo tratarían de desregular las economías nacionales y de favorecer la no 
interferencia de terceros en las leyes del mercado consideradas como naturales. En consecuencia, la globalización sería la última fase de un proceso de extensión planetaria de los mercados. Todo intento de limitar o de regular dicha expansión sería contemplado por las fuerzas que lo impulsan como una "distorsión" o "barrera" al natural desarrollo de la economía. Lo cual, afirman, no sería más que una forma de oscurecimiento de la verdadera naturaleza del proceso. Un proceso que lejos de responder a leyes inscritas en la naturaleza (tesis del intercambio comercial) descansa en los intereses de los colectivos e individuos que centralizan los beneficios del sistema.

\section{DISCUSIÓN}

Hasta el momento se han presentado las cuatro grandes tesis que coexisten en el espacio de discusión intelectual para explicar el proceso de globalización (véase un resumen en la Tabla 1, pág. 348). Todas ellas, pese a su popularidad y extensión, han sido objeto de duros ataques cruzados. Los defensores de una tesis suelen criticar a las demás, poniendo de relieve sus carencias a la hora de explicar el proceso de globalización pasado, presente o futuro. Se tratarán de resumir las críticas más frecuentes que se han formulado a cada una de las cuatro tesis.

\subsection{Críticas a la tesis del intercambio comercial}

Esta posición es la más controvertida y ha recibido gran cantidad de críticas. De hecho, en buena medida el resto de tesis surgió en confrontación con sus postulados. Las críticas se pueden agrupar en cinco grandes categorías: sobre sus presupuestos ideológicos, acerca de la naturalización del sistema económico, sobre el papel del Estado, sobre los resultados de la globalización y, finalmente, acerca del mecanismo que regula el comercio internacional.

En primer lugar, los críticos a esta tesis suelen afirmar que se presenta como una teoría científica, pero que en realidad es ampliamente ideológica. Suelen denominarla neoliberalismo, pensamiento único o fundamentalismo de mercado -también, en una denominación con menos éxito se le ha llamado "turbocapitalismo" (Luttwak, 2000) y en otra con mayor fortuna "capitalismo líquido" (Bauman, 2003)-. Piensan que esta ideología concibe la historia de un modo teleológico. El desarrollo de los mercados se contempla como el paso natural de los primeros y limitados mercados hasta el gran mercado abierto de la globalización. En todo caso, el mercado se considera una realidad natural preexistente, que solamente tiene que desarrollarse frente al Estado. La idea básica es que la globalización es un proceso espontáneo que si no se ve obstaculizado 
Tabla 1. Resumen de las cuatro tesis fundamentales en la explicación del proceso de globalización

\begin{tabular}{|c|c|c|c|c|}
\hline Tesis & $\begin{array}{l}\text { Causa principal } \\
\text { del proceso de } \\
\text { globalización }\end{array}$ & Motor del cambio & $\begin{array}{c}\text { Principales teorías } \\
\text { en que cristaliza } \\
\text { cada tesis }\end{array}$ & $\begin{array}{c}\text { Origen } \\
\text { aproximado del } \\
\text { proceso de } \\
\text { globalización } \\
\end{array}$ \\
\hline $\begin{array}{l}\text { Intercambio } \\
\text { comercial }\end{array}$ & \begin{tabular}{|c|} 
Extensión y \\
consolidación en \\
forma de \\
mercados de las \\
redes de \\
intercambio \\
comercial \\
\end{tabular} & $\begin{array}{l}\text { Propensión del } \\
\text { ser humano hacia } \\
\text { el trueque y } \\
\text { el intercambio }\end{array}$ & $\begin{array}{c}\text { Teoría de la ventaja } \\
\text { comparativa y } \\
\text { teoría del comercio } \\
\text { internacional }\end{array}$ & 3000-2000 a.C. \\
\hline Modernizadora & $\begin{array}{l}\text { Expansión de la } \\
\text { civilización } \\
\text { occidental }\end{array}$ & $\begin{array}{c}\text { Aparición } \\
\text { combinada de una } \\
\text { serie de } \\
\text { instituciones clave }\end{array}$ & $\begin{array}{c}\text { Teorías de la } \\
\text { modernización } \\
\text { y teoría de las } \\
\text { modernidades } \\
\text { múltiples }\end{array}$ & 1500 d.C. \\
\hline Tecnológica & $\begin{array}{l}\text { Invención y } \\
\text { mejora de las } \\
\text { comunicaciones } \\
\text { físicas y de } \\
\text { las TIC }\end{array}$ & $\begin{array}{l}\text { Extensión de las } \\
\text { facultades } \\
\text { comunicativas } \\
\text { del ser humano }\end{array}$ & $\begin{array}{c}\text { Teorías del } \\
\text { industrialismo } \\
\text { y teorías de la } \\
\text { sociedad de la } \\
\text { información }\end{array}$ & 1800 d.C. \\
\hline Capitalismo & \begin{tabular}{|c|} 
Expansión del \\
sistema \\
capitalista: dinero \\
y crédito, \\
intercambio \\
mercantil y \\
empresa privada
\end{tabular} & $\begin{array}{l}\text { Unión del poder } \\
\text { político y } \\
\text { económico para } \\
\text { crear un sistema } \\
\text { de mercado } \\
\text { autorregulado }\end{array}$ & $\begin{array}{c}\text { Teoría del } \\
\text { imperialismo, } \\
\text { teoría de la } \\
\text { dependencia y } \\
\text { teoría del } \\
\text { sistema mundial }\end{array}$ & 1980 d.C. \\
\hline
\end{tabular}

Fuente: elaboración propia

por el Estado (stateless global governance) conseguirá una mejora en todo el planeta mediante los mecanismos de la oferta y la demanda, que aseguran el equilibro de mercado, y la ventaja comparativa, que confiere un lugar en el comercio mundial a todas las naciones. Rechazan esta forma de contemplar la globalización, porque no refleja los hechos que se describen a continuación.

En segundo lugar, se ha combatido la idea de que la globalización es un proceso espontáneo. Suelen argüir que el mercado no es un orden espontáneo, sino que es una creación de los Estados o grupos políticos así como de los colectivos sociales interesados en su aparición y mantenimiento. La globalización estaría sustentada activamente por gobiernos, grupos financieros, industriales 
o terratenientes, es decir, por los agentes que se benefician de ella (Frieden, 2013). En este sentido existen fuerzas que contribuyen a la creación y desarrollo de la globalización. Aún aceptado que los actores influyen limitadamente en la globalización y que su actuación genera "consecuencias no intencionales", también sería cierto que parten de posición de poder diferenciales y que su actuación tiene un peso distinto en el proceso.

También se ha rechazado la idea de que el mercado sea una realidad natural, surgida en la antigüedad y desarrollada hasta la globalización actual. Como afirmó Karl Polanyi (1994), el libre mercado es un hecho específico y los intercambios en la antigüedad se encontraban regulados por otras formas institucionales que en nada se le parecen. Se sostiene, por tanto, que no es posible equiparar las formas actuales de intercambio propias de la globalización con las que se daban en el pasado. La circulación de bienes suntuarios en la Europa prehistórica (Kristiansen, 2001), el fenómeno del Kula entre los melanesios (Malinowski, 2001) o del Potlatch entre algunas tribus de la costa del Pacífico en Norteamérica (Mauss, 2009), no son situaciones que se expliquen según las leyes del mercado, aunque sí del intercambio. La confusión radicaría en confundir los sistemas de intercambio con el mercado. Otros autores afirman que no es posible equiparar la existencia de mercados con la del sistema capitalista (Braudel, 1985; George, 2010). Los primeros históricamente han existido sin que existiera un sistema capitalista que gobernara la economía de un territorio. Esta posición ya fue sustentada por Max Weber, para el cual:

Los mercados modernos no surgen de la "propensión natural al trueque, pago en especies e intercambio" descubierta por Adam Smith. Tampoco surgen de las elecciones racionales de los individuos. Para su surgimiento deben desarrollarse con anterioridad varias "condiciones sustantivas", tales como los modos racionales de contabilidad y administración, la promulgación de un derecho formal "interpretado y aplicado racionalmente" por juristas, el concepto de ciudadano, una ciencia y tecnología avanzadas, una ética económica moderna, la separación entre la economía doméstica y la de la empresa y la ausencia de monopolios absolutos en el mercado (Kalberg, 2008: 107).

Se ha afirmado, en tercer lugar, que es incierto considerar que el mercado exista o pueda existir sin el concurso del Estado. Diversos autores han señalado la importancia histórica del Estado en la gestación y mantenimiento del sistema capitalista y de los mercados asociados al mismo (Ingham, 2010; Polanyi, 2011; Rodrik, 2011; Wallerstein, 2012a). Max Weber incluso llegó a afirmar al hablar de los orígenes del capitalismo que "es, pues, el Estado racional cerrado el que procura al capitalismo las posibilidades de subsistencia” (2011: 341). Más recientemente Charles E. Lindblom ha afirmado que vista la evidencia, 
el sistema de mercado de nuestros días no es el laissez-faire de Adam Smith ni tampoco un sistema de mercado ligado a un Estado mínimo. Hoy, el sistema de mercado es un sistema dirigido, fuertemente cargado o adornado con lo que los partidarios del libre mercado de la vieja escuela describen despectivamente como "interferencias" (2002: 20).

Los mercados globales, argumentan, no han crecido "frente" a los Estados, más bien lo han hecho "con" los mismos. Los acuerdos de libre comercio han sido gestados por los Estados o al menos por los más poderosos. En este sentido, no son fruto de un mercado autorregulado y anónimo, aunque los agentes que juegan en el mercado interactúan con los Estados para consolidar su lógica y en esa actuación pueden contribuir a configurar los acuerdos interestatales

La cuarta crítica descansa en el resultado de la globalización. Se niega que la ley de la oferta y la demanda conduzcan a una convergencia planetaria real. Se ha afirmado que la idea de un mercado autorregulado que llega a un equilibrio -que debemos entre otros a economistas como Adam Smith, Vilfredo Pareto (1848-1923) o Leon Walras (1834-1910)-, solo funciona aplicando una serie de presupuestos abstractos simplificados, por ejemplo, que todos los agentes tienen una información perfecta y completa sobre la situación del mercado, lo cual no tiene correlato con la realidad. Los agentes económicos más bien parecen convivir permanentemente con una situación donde predomina la información imperfecta o distorsionada (Stiglitz, 2002). Cuando se aplican modelos matemáticos complejos, con simulaciones mediante ordenador, para analizar la emergencia de sistemas como el comercio internacional, el resultado tiene a ser distinto del que los modelos económicos ortodoxos pronostican (Ball, 2008). La distribución no termina siendo óptima y se suele producir un aumento de la desigualdad de renta entre los actores implicados, no una reducción de la misma.

Por último, en la que es quizá la crítica de mayor calado, también se ha discutido el mecanismo que según la economía ortodoxa explicaría el equilibro en los mercados internacionales: la ventaja comparativa. Los economistas Wolfgang Stolper (1912-2002) y Paul Samuelson (1915-2009) argumentaron en 1941 que el comercio internacional era beneficioso para algunos actores y perjudicial para otros dentro del mismo contexto geográfico. Los exportadores de un factor de producción abundante en una nación se beneficiaban del comercio, mientras que los productores de un bien escaso sufrían la competencia de productos extranjeros - provenientes de entornos donde eran abundantes- que terminaban arruinándolos. Esto suponía que dentro de una nación había ganadores y perdedores, aun cuando el cómputo total para la economía pudiese resultar beneficioso (Frieden, 2013: 152-155). 
Apenas unos años más tarde, en 1944, Karl Polanyi (1886-1964) publicó La gran transformación en la que retomaba parcialmente estas tesis al afirmar que el libre comercio y el sistema de mercado producían graves dislocaciones sociales. La consecuencia era que la sociedad debía "autoprotegerse". Obviamente, quienes se autoprotegían eran aquellos que perdían con el intercambio. Así, los países europeos durante la primera globalización protegieron a sus agricultores en desventaja frente a las importaciones, mientras que las revueltas antiimperialistas representaban en muchas ocasiones a las clases productores locales que no podían competir con las exportaciones de las metrópolis (Polanyi, 2011: 243). Y todo eso aún a expensas de una mejora económica global, ya que el sufrimiento de un sector específico de la economía podía condicionar una desorganización social inasumible para el conjunto de la sociedad. En este sentido, Dani Rodrik (2011) ha llegado a afirmar que la globalización económica tal como aparece hoy día es incompatible con la democracia y el Estado-nación.

Actualmente algunos autores consideran que la ventaja comparativa no se encuentra respaldada ni por la evidencia empírica, ni por el análisis racional. Los datos disponibles muestran que en general el crecimiento económico precede más que acompaña a la apertura del comercio internacional, que los países más exitosos suelen ser puertos francos comerciales y que las economías con corporaciones multinacionales pertenecen a países que han defendido sus intereses al tiempo que mantenían su centro independiente con un Estado fuerte. Además, los países que se especializaban en un nicho de mercado habitualmente no han tenido la capacidad de reconvertirse cuando este nicho fallaba por algún motivo (Mangabeira Unger, 2011: 33-35). Habría que sumar que la teoría de la ventaja comparativa está basa en un presupuesto teórico cuestionable: el nacionalismo metodológico. Es decir, soslaya el hecho de que muchos de los intercambios comerciales se producen dentro y entre grandes corporaciones transnacionales que operan por todo el planeta superando los límites territoriales de las naciones.

\subsection{Críticas a la tesis modernizadora}

La principal crítica que se ha realizado a esta tesis es que entiende la modernidad como un "paquete", en el que todos los elementos han de estar presentes (Jones, 2006). Algunos autores consideran que la globalización económica no precisa del resto del "aparato institucional" para triunfar y que "nunca ha habido la menor probabilidad de que las numerosas variedades de capitalismo se vieran sustituidas por una pálida monocultura anglosajona" (Gray, 2004: 81). En este sentido, Roberto Mangabeira Unger (2011) sugiere que no existe 
un único sistema de mercado, ya que cada nación presenta formas institucionales específicas que además pueden cambiar con el tiempo.

También se ha criticado que esta concepción es excesivamente eurocéntrica y que estas teorías, comunes dentro de la sociología, suelen ser un discurso centrado en el "norte" rico. No incluye visiones alternativas surgidas desde los países no centrales (Connell, 2007). Conceptos como capitalismo, democracia, mercado o modernidad han sido creados para imponer la visión occidental del mundo y ocultan otras realidades y otros modos de vida. Jack Goody $(2011,2012)$ ha descrito la aparición de la modernidad como un proceso de interconexión entre las economías y las culturas del gran continente Euroasiático. En el mismo, algunas partes del continente adquirieron ventaja temporal en función de los flujos comerciales y de intercambio de ideas. En algunos momentos algunas regiones tomaron la delantera, pero al estar las culturas en un proceso de "constante comunicación", los avances tienden a igualarse con el tiempo. No puede afirmarse, por tanto, que Occidente o Europa tengan instituciones singulares y únicas. Simplemente han disfrutado de un momento de bonanza temporal que ahora parece estarse igualando.

Por último, se ha planteado que desde este modelo no se pueden hallar relaciones causales, pues las diferentes dimensiones institucionales o culturales son vistas como causas y resultados de la globalización al mismo tiempo. La globalización supone una extensión mundial de todas las dimensiones de la modernidad, pero no queda claro cuáles son los factores impulsores del proceso en un momento concreto, ni el peso de los mismos en caso de operar al mismo tiempo. Las teorías modernistas suelen reprochar al resto de puntos de vista su determinismo y es frecuente que busquen explicar la globalización como un proceso conducido por un conjunto de relaciones e instituciones diversas (Kellner, 2002). Sin embargo, el problema radicaría en determinar y definir esas instituciones, sobre las que no hay acuerdo. Además, las culturas tienen tal grado de complejidad interna que es difícil saber qué instituciones son importantes para el desarrollo económico en concreto (de la Dehesa, 2006) y para la extensión de un sistema civilizatorio como la modernidad en general.

\subsection{Críticas a la tesis tecnológica}

A esta postura se le ha achacado sobre todo el caer en un determinismo tecnológico, del estilo del practicado por Marshall McLuhan (1993). Así, la primera modernidad y el primer proceso de globalización se explicaban apelando a la máquina de vapor y la globalización actual a Internet. Respecto a la explicación de la modernidad en términos tecnológicos replicaba Edward P. Thompson (1989) que era imposible entender la modernidad como la suma de la máquina 
de vapor y la organización fabril, ya que en la misma estaban implicados factores sociales, culturales y políticos además de económicos. Y Raymond Williams (1974) apuntaba que no existe una determinación tecnológica directa, pues toda tecnología se haya inserta en un contexto social específico.

Posteriormente, como se mantuvo antes, se pasó a centrar el foco en las TIC, que fueron vistas como la base tecnológica que permite la ampliación de los intercambios y del comercio. Frente a esto, los críticos consideran que la tecnología no es una variable independiente, sino un elemento interrelacionados con "los deseos, las costumbres, las ideas y las metas" (Mumford, 1998: 22). Es decir, las tecnologías no sería la causa de la globalización. Al contrario, el proceso de interconexión global sería el acicate para el desarrollo de las tecnologías de la comunicación.

\subsection{Críticas a la tesis del capitalismo}

Este planteamiento ha sido criticado primariamente por contemplar la globalización como un proceso dirigido por "nuevos amos" (Ziegler, 2013), unas "castas rápidas" (George, 2010), una "aristocracia del dinero" (Corm, 2012) o los "Davos Man" (Robinson, 2013). La idea de que ciertos colectivos controlan el mercado global es vista como una irrealidad cercana a las más rancias tesis del complot. Un ejemplo clásico de estas teorías sería la descripción de Carroll Quigley (1981) del Milner Group durante la primera globalización y durante la segunda el llamado Club Bilderberg (Estulin, 2005). Los críticos a esta posición mantienen que esto simplemente no puede ser cierto, ya que cualquier interferencia en el desarrollo natural de los mercados es un proceso de "ingeniería social", que obstaculiza su progreso e impide la extensión de las ventajas de la globalización por todo el planeta. No es posible controlar la globalización, pues surge de un modo natural de las miles de intercambios no planificados que realizan los seres humanos por todo el planeta. De hecho, incluso algunos autores críticos con la globalización aceptan la legitimidad de la misma, pues no sería posible ver la globalización como una conspiración de los poderosos. Mantienen, sin embargo, que está configurada del modo en que lo está porque refleja los intereses de la comunidad financiera internacional (Stiglitz, 2002).

Asimismo se han realizado toda una serie de invectivas sobre los fundamentos ideológicos de esta posición (Bhagwati, 2004: 13-27). Se ha afirmado que es una posición anticapitalista, que siente nostalgia de posiciones fracasadas, y que se encuentra asentada en disciplinas como la literatura, los estudios culturales o la sociología (pero no en la economía). También se liga con los movimientos contrarios al imperialismo, anticolonialistas y antiestadounidenses, y 
a la lucha contra las corporaciones transnacionales. Estos movimientos estarían dentro de la izquierda política, pero también se encuentran en la derecha desde posiciones que apoyan en comunitarismo y la sociedad civil frente al poder disgregador del capitalismo. En todo caso, se achacaría a esa posición su fundamento claramente ideológico, que no se corresponde con la evidencia empírica y con los efectos beneficiosos de la globalización.

Finalmente se ha criticado que aunque es frecuente afirmar que quienes más sufren las consecuencias negativas del proceso de globalización son los pobres en las economías menos avanzadas y los obreros no cualificados de las avanzadas (Bauman, 1998), la globalización puede beneficiar en algunos aspectos más a los países pobres que a los más ricos, por ejemplo mediante la destrucción de empleos industriales en los últimos y su traslado a los primeros (Munck, 2002). El computo final podría ser más beneficioso para los países menos desarrollados que para los más avanzados. Dicho de otro modo, la globalización sería más un transferencia que una polarización de la riqueza.

\section{CONCLUSIONES}

Este artículo ha tratado de elaborar un modelo meta-teórico con objeto de analizar las principales tesis sobre el proceso de globalización. Para ello se ha creado una tipología que en función del mecanismo explicativo fundamental encuentra cuatro grandes aproximaciones. En primer lugar, la tesis del intercambio comercial para la cual la globalización es producto del comercio y de la propensión natural del ser humano hacia el trueque. En segundo lugar, la tesis modernizadora que describe la globalización como el proceso de extensión de un modelo civilizatorio europeo u occidental. En tercer lugar, la tesis tecnológica que encuentra en la mejora de los medios de comunicación físicos y virtuales la principal explicación del proceso de mundialización. Y finalmente la tesis del capitalismo que mantiene que la creación de un sistema económico específico y su posterior extensión por todo el planeta explican la globalización.

Las cuatro tesis exploradas operan en dos niveles de abstracción. El primero describe la causa de la globalización en función de dos variables relativamente simples y homogéneas: la tecnología o el intercambio comercial. El incremento de esas variables conduce inevitablemente a la globalización. El segundo busca modelos multicausales, que habitualmente combinan estas variables simples en modelos analíticamente más complejos. De este modo el capitalismo es definido como una construcción que aúna varias instituciones: intercambio comercial, mercados, dinero, crédito y empresa privada. La modernidad implicaría, entro otros rasgos institucionales, nuevas tecnologías, una economía 
capitalista, un Estado democrático y racional, una ciudadanía activa y una sociedad culturalmente secular e individualista. La combinación de dichas variables, en diverso grado, sería el mecanismo que explicase el proceso de globalización. En todo caso, todas estas teorías quedan unificadas por su intento de constituirse en una "gran teoría" que explique el proceso de globalización como un todo.

Esta gran teoría trata de crear un relato totalizador y que proporcione una "causa primera" a las explicaciones sobre los fenómenos sociales de nuestro tiempo. En este sentido es una teoría profundamente imbuida en el pensamiento moderno. Por este motivo ha sido objeto de ataques desde la teoría posmoderna que más que rechazar aspectos concretos de las tesis expuestas, tienden a rechazar la posibilidad de una teoría de la globalización como un todo. Para los posmodernistas, el tiempo de los grandes relatos ya pasó. Estos suelen ser más una legitimación del proceso, creada por varones caucásicos, que una verdadera descripción de las dinámicas mundiales. Excluyen, por tanto, a los pueblos no occidentales, que son obligados a participar en un relato construido desde y para occidente.

Asimismo, un rasgo característico de la teoría de la globalización es que habitualmente aúna aspectos normativos y de facto. En este sentido, la teoría de la globalización se constituye en una poderosa justificación de la acción económica, política o social y crea un virulento debate entre aquellos que apoyan el proceso y los que lo rechazan. En definitiva, la teoría de la globalización como se ha reflejado afronta tanto problemas concretos como generales, que hacen que su capacidad analítica y descriptiva sea limitada. Su éxito puede radicar más en la capacidad de elaborar un mapa cognitivo de enorme valor para los miembros de sociedades inmersas en profundos y acelerados cambios económicos, políticos y culturales, que en su capacidad analítica para describir esa realidad en términos científicos.

\section{BIBLIOGRAFÍA}

Albert, M. (2007). "Globalzation theory: Yesterday's fad or more lively than ever?". International Political Sociology, 1 (2), 165-182.

Al-Rodhan, N. R. F. (2006). Definitions of Globalization. A Comprehensive Overview and a Proposed Definition. Geneva: GCSP.

Amin, S. (1976). Sobre el desarrollo desigual de las formaciones sociales. Barcelona: Anagrama.

Amin, S. (1993). Capitalismo y sistema mundo. Barcelona: Lafarga.

Amin, S. (1997). Los desafios de la mundialización. México: Siglo XXI.

Amin, S. (1998). El capitalismo en la era de la globalización. Barcelona: Paidós. 
Anderson, J., Brook, C. y Cochrane, A. (Eds.) (1995). A Global World? Re-ordering Political Space. Milton Keynes: The Open University-Oxford University Press.

Appadurai, A. (1996). Modernity at Large. Cultural Dimensions of Globalization. Minneapolis: University of Minesota Press.

Augé, M. (2000). Los no lugares. Espacios del anominato. Una antropología de la sobremodernidad. Barcelona: Gedisa.

Barber, B. R. (1996). Jihad Versus McWorld. How Globalism and Tribalism are Reshaping the World. New York: Ballantine Books.

Ball, P. (2008). Masa crítica. Cambio, caos y complejidad. Madrid-México: Turner-FCE.

Bauman, Z. (1998). Globalization. The Human Consequences. New York: Columbia University Press.

Bauman, Z. (2003). Modernidad líquida. México: FCE.

Bayly, C. A. (2010). El nacimiento del mundo moderno. 1780-1914. Conexiones y comparaciones globales. Madrid: Siglo XXI.

Beck, U. (2000). What is Globalization? Cambridge: Polity.

Berger, P. y Huntington, S. (Eds.) (2002). Many Globalizations. Cultural Diversity in the Contemporary World. Oxford: Oxford University Press.

Bhagwati, J. (2004). In Defense of Globalization. Oxford: Oxford University Press.

Boli, J. y Lechner, F. J. (2009). "Globalization theory". En B. S. Turner (Ed.), The New Blackwell Companion to Social Theory. Oxford: Blackwell, 321-340.

Braudel, F. (1985). La dinámica del capitalismo. Madrid: Alianza.

Bude, H. y Durrschmidt, J. (2010). "What's wrong with globalization? Contra "flow speak-towards an existential turn in the theory of globalization", European Journal of Social Theory, 13 (4), 481-500.

Cairncross, F. (1997). The Death of Distance. How the Communications Revolution will Change Our Lives. Boston: Harvard Business School Press.

Castells, M. (2000). La era de la información. Economía, sociedad y cultura. Vol. 1. La sociedad red. Madrid: Alianza.

Cebrián, J. L. (2000). La red. Barcelona: Suma de Letras.

Connell, R. (2007). "The Northern theory of globalization", Sociological Theory, 25 (4), 368-385.

Corm, G. (2012). El nuevo gobierno del mundo. Ideologías, estructuras, contrapoderes. Barcelona: Península.

Crozier, M. J., Huntington, S. P. y Watanuki, J. (2012). "The crisis of democracy. Report on the governability of democracies to the Trilateral Commission", Sociología histórica, 1, 311-329.

Curran, J. y Park, M.-J. (2000). "Beyond globalization theory". En J. Curran y M.-J. Park (Eds.), De-Westernizing Media Studies. London: Routledge, 2-15.

de la Dehesa, G. (2006). Winners and Losers in Globalization. New York: Blackwell.

de la Dehesa, G. (2007). What do we Knew about Globalization? Issues of Poverty and Income Distribution. Oxford: Blackwell.

Echeverría, J. (1999). Los señores del aire. Telépolis y el tercer entorno. Barcelona: Destino. 
Eisenstadt, S. N. (2010). "Las dimensiones del análisis comparativo y el estudio de las dinámicas sociales: de la política comparada al análisis comparado de civilizaciones". En J. Schriewer y H. Haelble (Comps.), La comparación en las ciencias sociales e históricas. Un debate interdisciplinar. Barcelona: Octaedro e ICE-UB, 85-105.

Estulin, D. (2005). La verdadera historia del Club Bilderberg. Barcelona: Ediciones del Bronce.

Ferguson, N. (2012). Civilización. Occidente y el resto. Barcelona: Crítica.

Frieden, J. A. (2013). Capitalismo global. El transfondo económico de la historia del siglo XX. Barcelona: Crítica.

Friedman, J. (2003): "Los liberales de champagne y las nuevas clases peligrosas: reconfiguraciones de clase, identidad y producción cultural". En J. L. García y A. Barañano (Coords.), Culturas en contacto. Encuentros y desencuentros. Madrid: Ministerio de Educación, Cultura y Deporte, 161-197.

García Canclini, N. (2001). Culturas híbridas. Estrategias para entrar y salir de la modernidad. Barcelona: Paidós.

George, S. (2010). El informe Lugano. Barcelona: Icaria e Intermón-Oxfam.

Giddens, A. (1993). Consecuencias de la modernidad. Madrid: Alianza.

Giddens, A. (2000). Runaway World. How Globalization is Reshaping our Lives. London: Routledge.

Goody, J. (2011). El robo de la historia. Madrid: Akal.

Goody, J. (2012). El milagro euroasiático. Madrid: Alianza.

Gray, J. (2004). Al Qaeda y lo que significa ser moderno. Barcelona: Paidós.

Harvey, D. (2008). La condición de la posmodernidad. Investigación sobre los orígenes del cambio cultural. Buenos Aires: Amorrortu.

Held, D. y McGrew, A. (2002). Globalization/Anti-Globalization. Cambridge: Polity Press.

Held, D. y McGrew, A. (Eds.) (2007). Globalization Theory: Approaches and Controversies. Cambridge: Polity Press.

Huerta de Soto, J. (2010). La Escuela Austriaca. Mercado y creatividad empresarial. Madrid: Síntesis.

Ingham, G. (2010). Capitalismo. Madrid: Alianza.

Jones, E. L. (2006). Cultures Merging. A Historical and Economic Critique of Culture. Priceton: Priceton University Press.

Jones, A. (2010). Globalization. Key Thinkers. Cambridge: Polity.

Kalberg, S. (2008). Max Weber. Principales dimensiones de su obra. Buenos Aires: Prometeo.

Kellner, D. (2002). "Theorizing globalization”, Sociological Theory, 20 (3), 285-305.

Kristiansen, K. (2001). Europa antes de la historia. Los fundamentos prehistóricos de la Europa de la Edad de Bronce y de la primera Edad del Hierro. Barcelona: Península.

Langhorne, R. (2001). The Coming of Globalization. Its Evolution and Contemporary Consequences. Basingstoke: Palgrave.

Lindblom, C. E. (2002). El sistema de Mercado. Qué es, cómo funciona y cómo entenderlo. Madrid: Alianza. 
Luttwak, E. (2000). Turbocapitalismo. Quiénes ganan y quiénes pierden en la globalización. Crítica: Barcelona.

Malinowski, B. (2001). Los argonautas del Pacífico occidental. Comercio y aventura entre los indígenas de la Nueva Guinea melanésica. Barcelona: Península.

Mangabeira Unger, R. (2011). La reinvención del libre comercio. La división mundial del trabajo y el método de la economía. Buenos Aires: FCE.

Martín-Cabello, A. (2013). "Sobre los orígenes de la globalización", methaodos.revista de ciencias sociales, 1: 7-20.

Mauss, M. (2009). Ensayo sobre el don. Forma y función del intercambio en las sociedades arcaicas. Buenos Aires: Katz.

McLuhan, M. (1993). La galaxia Gutenberg. Génesis del "Homo Typographicus”. Barcelona: Galaxia Gutenberg-Círculo de Lectores.

Munck, R. (2002): "Globalization: Deconstruction and beyond", Latin American Perspectives, 29 (6), 24-31.

Mumford, L. (1998). Técnica y civilización. Madrid: Alianza.

Negroponte, N. (1995). Being Digital. New York: Alfred A. Knopf.

Polanyi, K. (1994). El sustento del hombre. Barcelona: Mondadori.

Polanyi, K. (2011). La gran transformación. Los orígenes políticos y económicos de nuestro tiempo. México: FCE.

Quigley, C. (1981). The Anglo-American Establishment: From Rhodes to Cliveden. New York: Books in Focus.

Ravier, A. O. (2012). La globalización como orden espontáneo. Madrid: Unión Editorial.

Reyes, G. E. (2001). "Teoría de la globalización. Bases fundamentales", Nómadas. Revista crítica de ciencias sociales y jurídicas, 3, 173-180.

Ritzer, G. (2004). The Globalization of Nothing. Thousand Oaks, CA: Sage.

Robertson, R. (1992). Globalization. Social Theory and Global Culture. London: Sage.

Robertson, R. (2001). "Globalization theory 2000+: Major problematics". En G. Ritzer, y B. Smart (Eds.). Handbook of Social Theory. London: Sage, 458-471.

Robinson, A. (2013). Un reportero en la montaña mágica. Cómo la élite económica de Davos hundió el mundo. Barcelona: Ariel.

Robinson, W. I. (2011). "Globalization and the sociology of Immanuel Wallerstein: A critical appraisal”, International Sociology, 26 (6), 723-745.

Rodrik, D. (2011). La paradoja de la globalización. Democracia y el futuro de la economía mundial. Barcelona: Antoni Bosch.

Rosenberg, J. (2005). "Globalization Theory: A Post Mortem", International Politics, 42, 2-74.

Safranski, R. (2005). How Much Globalization can we bear? Cambridge: Polity.

Stiglitz, J. E. (2002). Globalization and its Discontents. New York: W. W. Norton.

Stiglitz, J. E. (2006). Making Globalization Work. New York: W. W. Norton.

Stohl, C. (2005): "Globalization theory". En S. May y D. K. Mumby (Eds.), Engaging Organizational Communication. Theory and Research. London: Sage, 22-261. 
Thompson, E.P. (1989). Tradición, revuelta y consciencia de clase. Estudios sobre la crisis de la sociedad preindustrial. Barcelona: Crítica.

Trigo, A. (2004). What Do you Mean by "Cultural Globalization"? Bowling Green, Ohio: Working Paper Series on Historical Systems, Peoples and Cultures, 17.

Urry, J. (2002). Global Complexity. Cambridge: Polity.

Virilio, P. (1997). Open Sky. London: Verso.

Wallerstein, I. (1999). El moderno sistema mundial. Vol.2. El mercantilismo y la consolidación de la economía-mundo europea, 1600-1750. México: Siglo XXI.

Wallerstein, I. (2011a). El moderno sistema mundial. Vol. 1. La agricultura capitalista y los orígenes de la economía mundo europea en el siglo XVI. México: Siglo XXI.

Wallerstein, I. (2011b). The Modern World System. Vol. 4. Centrist Liberalism Triumphant, 1789-1914. Berkeley: University of California Press.

Wallerstein, I. (2012a). El capitalismo histórico. Madrid: Siglo XXI.

Wallerstein, I. (2012b). El moderno sistema mundial. Vol. 3. La segunda era de gran expansión de la economía-mundo capitalista, 1730-1850. México: Siglo XXI.

Weber, M. (1998). La ética protestante y el espíritu del capitalismo. Madrid: Istmo.

Weber, M. (2011). Historia económica general. México: FCE.

Williams, R. (1974). Television: Technology and Cultural Form. London: Fontana.

Williamson, J. (1993). "Democracy and the «Washington Consensus»", World Development, 21 (8), 1329-1336.

Ziegler, J. (2013). Los nuevos amos del mundo. Y la lucha de aquellos que se resisten a dejarse engullir por la globalización. Barcelona: Destino.

ANTONIO MARTIN CABELLO es licenciado y doctor en Sociología por la Universidad Pontificia de Salamanca y posee un Master en Gestión de Recursos Humanos por la Universidad San Pablo-CEU. Amplió estudios en la University of Central England en Birmingham (Reino Unido). Tras su paso por la empresa privada, ha sido profesor de Sociología en la Universidad Alfonso X el Sabio (Madrid) y en la actualidad ejerce su labor docente en la Universidad Rey Juan Carlos (Madrid). También ha sido profesor e investigador invitado en la Universidad Alberto Hurtado (Santiago de Chile), en la HumboldtUniversität zu Berlin (Alemania) y en la Università degli Studi Roma "Tor Vergata" (Italia). Es miembro del grupo de investigación methaodos.org y director adjunto de methaodos.revista de ciencias sociales. Sus líneas de investigación se centran en la sociología de la cultura, los estudios culturales y el fenómeno de la globalización.

Recibido: $20 / 11 / 2014$

Aceptado: 12/12/2014 